\title{
The Role of Tropospheric Rossby Wave Breaking in the Pacific Decadal Oscillation
}

\author{
COURTENAY STRONG AND GUDRUN MAGNUSDOTTIR
}

University of California, Irvine, Irvine, California

(Manuscript received 16 April 2008, in final form 15 September 2008)

\begin{abstract}
The leading pattern of extratropical Pacific sea surface temperature variability [the Pacific decadal oscillation (PDO)] is shown to depend on observed variability in the spatiotemporal distribution of tropospheric Rossby wave breaking (RWB), where RWB is the irreversible overturning of potential vorticity on isentropic surfaces. Composite analyses based on hundreds of RWB cases show that anticyclonic (cyclonic) RWB is associated with a warm, moist (cool, dry) column that extends down to a surface anticyclonic (cyclonic) circulation, and that the moisture and temperature advection associated with the surface circulation patterns force turbulent heat flux anomalies that project onto the spatial pattern of the PDO. The RWB patterns that are relevant to the PDO are closely tied to El Niño-Southern Oscillation, the Pacific-North American pattern, and the northern annular mode. These results explain the free troposphere-to-surface segment of the atmospheric bridge concept wherein El Niño anomalies emerge in summer and modify circulation patterns that act over several months to force sea surface temperature anomalies in the extratropical Pacific during late winter or early spring. Leading patterns of RWB account for a significant fraction of PDO interannual variability for any month of the year. A multilinear model is developed in which the January mean PDO index for 1958-2006 is regressed upon the leading principal components of cyclonic and anticyclonic RWB from the immediately preceding winter and summer months (four indexes in all), accounting for more than two-thirds of the variance.
\end{abstract}

\section{Introduction}

The Pacific decadal oscillation (PDO) is the leading pattern of extratropical Pacific sea surface temperature (SST) variability (Mantua et al. 1997). It affects climate in the pan-Pacific basin (Dettinger et al. 1998; Cayan et al. 1998; Mantua and Hare 2002) and significantly influences Pacific marine ecosystems (e.g., Mysak 1986). The spatial pattern of the PDO is shown in Fig. 1a. During the positive polarity of the PDO, SSTs are anomalously low over the central Pacific between $30^{\circ}$ and $45^{\circ} \mathrm{N}$ and anomalously high along the west coast of North America. We will refer to the light-shaded area as the "PDO cool region" and the dark-shaded area as the "PDO warm region." The PDO index (PDOI) has energy on many different time scales as seen in Fig. 1b, with decadal time scales providing an important component of the signal (Mantua et al. 1997; Minobe 1997,

Corresponding author address: Courtenay Strong, Department of Earth System Science, University of California, Irvine, Irvine, CA 92697-3100.

E-mail: cstrong@uci.edu
1999). In the results presented here, we do not apply any filters to the PDOI and consider its full spectrum of variability.

There is ongoing interest in understanding the PDO and the physical processes that may drive it (review by Alexander et al. 2002; Liu and Alexander 2007). The major competing hypotheses recognize the atmosphere as an important component, often in connection with $\mathrm{El}$ Niño-Southern Oscillation (ENSO). Zhang et al. (1996) examined extratropical Pacific SST variability after removing the portion linearly dependent on ENSO, and found it to be strongly coupled to the atmosphere's Pacific-North American pattern (PNA) described by Wallace and Gutzler (1981). The PNA is a prominent pattern of extratropical climate variability that is internal to the atmosphere but with a probability distribution that is strongly affected by ENSO (Straus and Shukla 2002; Yu et al. 2007). The positive polarity of the PNA is associated with an extension of the East Asian jet exit region toward the western United States, and the negative PNA is associated with a retracted East Asian jet with split flow and ridging over the North Pacific and western North America. Lau and Nath (1996) introduced 

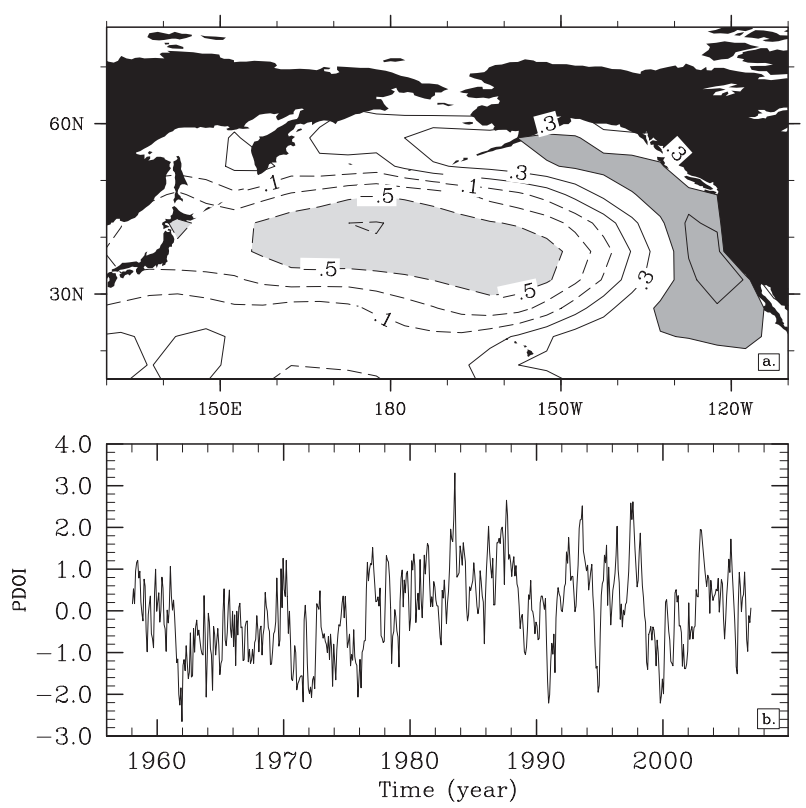

FIG. 1. (a) Correlation between monthly SST anomalies and the monthly PDOI. The "PDO cool region" is shown with light shading, and the "PDO warm region" is shown with dark shading. (b) The monthly PDOI.

the concept of an "atmospheric bridge" from ENSO to the PDO by showing how ENSO-correlated shifts in geopotential height, lower-tropospheric humidity and temperature, and surface pressure and winds are consistent with the spatial and temporal pattern of the PDO on a seasonal-mean basis in observations and simulations.

Modeling studies indicate that approximately $1 / 4$ to $1 / 2$ of the variance of the dominant pattern of decadal, extratropical Pacific SST variability is associated with the atmospheric bridge from ENSO, with changes in net surface heat flux being the dominant factor (Alexander et al. 2002; Liu and Alexander 2007). Schneider and Cornuelle (2005) showed that more than $80 \%$ of the winter-centered, annually averaged PDOI could be recovered from an autoregressive model of SST anomalies forced by ENSO, Aleutian low variability, and oceanic zonal advection anomalies in the Kuroshio-Oyashio Extension.

Some recent research on the PDO is drawing attention to the role of atmospheric weather noise, both with respect to the index itself and the processes that may drive the index. Developing and analyzing a multivariate empirical model of the PDO, Newman (2007) limited the predictability of the PDO to little more than a year, and suggested that it represents not a single physical mode but rather the sum of several basin-scale processes, each with a different spatial pattern and autocorrelation time scale. Yeh and Kirtman (2004) demonstrated the strong sensitivity of North Pacific SST variance to stochastic forcing from internal atmospheric dynamics or weather noise. They used an interactive ensemble coupling strategy (Kirtman and Shukla 2002) to control the amplitude of atmospheric noise occurring over the ocean at the air-sea interface without affecting the atmospheric dynamics. Their results suggest that atmospheric noise drives much of the North Pacific SST variability, particularly within the northern subpolar gyre including the Kuroshio Extension and the subtropical gyre in the central part of the North Pacific. In a followup study, Yeh et al. (2007) found that extratropical atmospheric noise dominates the findings in Yeh and Kirtman (2004) but hypothesized that tropical atmospheric noise modulates ENSO, which in turn affects North Pacific SSTs through the atmospheric bridge.

What is implicit in, and may serve toward unifying, the collective body of results described above is the existence of an atmospheric phenomenon that meets the following three criteria: 1) it systematically generates organized patterns of surface turbulent heat flux that project onto the PDO spatial pattern; 2) it has a spatiotemporal distribution that varies with above-suggested drivers of the PDO such as ENSO, the PNA, and the northern annular mode (NAM); and 3) it is common over the Pacific basin and quasi-stationary so as to provide locally persistent forcing. Here, we suggest that tropospheric Rossby wave breaking (RWB) is this very mechanism, where RWB is the large-scale, irreversible overturning of potential vorticity (PV) on isentropic surfaces (McIntyre and Palmer 1983). Concerning the three criteria listed above, respectively, 1) we will show that RWB involves a deep, coherent three-dimensional structure that forces organized patterns of turbulent heat flux at the air-sea interface. 2) RWB has previously been connected to upper-level jet variability associated with ENSO (Abatzoglou and Magnusdottir 2006), the PNA (Orlanski 2005; Martius et al. 2007), and the NAM (Strong and Magnusdottir 2008). 3) As a propagating wave breaks, its phase speed tends to slow, lengthening the time over which it can regionally influence surface heat exchange.

Following a description of data and our RWB analysis method (section 2), there are three results sections (3-5). Section 3 is primarily a statistical analysis of the relationship between the PDO and RWB for all months of the year at various lags. Based on the lagged analysis, we select the January PDOI for detailed study, and model it using objective indexes of RWB from immediately preceding summer and winter months. Section 4 illustrates the physical processes underlying the statistical relationships shown in section 3 . We use composite analyses to show that cyclonically and anticyclonically 
breaking waves have well-defined three-dimensional structures that force surface advection patterns that impact heat exchange at the air-sea interface. In section 5 , we identify regions where RWB variability most strongly influences the PDO and show how placement of RWB in these regions projects coherent surface flux anomaly patterns onto the PDO spatial pattern.

\section{Data and methods}

\section{a. Data}

From the 6-hourly, $2.5^{\circ} \times 2.5^{\circ} \mathrm{NCEP}-\mathrm{NCAR}$ reanalysis for years 1958-2006, we studied RWB on four isentropic surfaces: $330,350,400$, and $450 \mathrm{~K}$. Results from $350 \mathrm{~K}$ were found to be representative uppertropospheric RWB and form the basis of the research presented here. From mandatory isobaric surfaces, we use temperature $(T)$, specific humidity $(q)$, and velocity $(u, v, \omega)$. To quantify near-surface processes, we use $u$ and $v$ at $\sigma=0.995$ and a turbulent heat flux $\left(F_{t}\right)$, which is the sum of the reanalysis net latent and sensible heat fluxes (positive into the atmosphere). The data $F_{t}$ are based on model parameterizations and may contain significant systematic errors over portions of the Pacific. Moore and Renfrew (2002) found the greatest discrepancies between modeled and observed $F_{t}$ over the ocean's western boundary currents, but also found that the surface-layer meteorological fields are well represented. We will thus examine composite anomalies of low-level temperature, moisture, and wind associated with RWB and check that the composite spatial patterns of $F_{t}$ are in sign agreement with these anomalies, focusing on the portion of the Pacific outside the western boundary currents.

For the PDOI, we use 1958-2006 SSTs projected onto the leading empirical orthogonal function (EOF) of monthly Pacific SSTs poleward of $20^{\circ} \mathrm{N}$, which we obtained from the University of Washington server (Mantua et al. 1997). For monthly SST anomalies, we use National Oceanic and Atmospheric Administration (NOAA) Extended Reconstructed SST V2 data obtained from the Earth System Research Laboratory (ESRL) at http://www. cdc.noaa.gov/. To quantify the NAM, we use the NOAA Climate Prediction Center (CPC) Arctic Oscillation index, which is constructed by projecting daily $1000-\mathrm{hPa}$ geopotential height $(Z)$ anomalies poleward of $20^{\circ} \mathrm{N}$ onto the leading EOF of monthly-mean $1000-\mathrm{hPa} Z$ for the 1979-2000 period. We use the CPC PNA index (PNAI), which is based on rotated EOFs of $500-\mathrm{hPa} Z$. To quantify the El Niño-Southern Oscillation, we use the multivariate ENSO index (MEI; Wolter and Timlin 1993) obtained from NOAA ESRL.

\section{b. Wave-breaking variables}

A detailed description of our RWB analysis method is given in Strong and Magnusdottir (2008). Here, we briefly describe the method using the instance of anticyclonic PV overturning in Fig. 2a and instance of cyclonic PV overturning in Fig. 2b as illustrative examples. Our method yields the relative frequency of PV overturning within equal-area spatial bins (which is intentionally different from tracking and counting wavebreaking events as they move through space). We identify contiguous blocks of meridians where low-PV air is bounded by an overturned PV contour (the method generalizes to identifying contiguous blocks of meridians where high-PV air is bounded by an overturned PV contour). The areas containing the contiguous blocks of low PV are shaded in Figs. 2a,b, and the centroid of each shaded area is marked by a filled circle.

To quantify the amount of PV overturning over a particular region, we divide the Northern Hemisphere into $H=400$ equal-area bins and calculate the relative frequency of anticyclonic centroids $\left(\gamma_{a}\right)$ and cyclonic centroids $\left(\gamma_{c}\right)$ in each bin over two consecutive months. We found two months to be a useful window for this analysis, balancing degrees of freedom against the sharpness with which we resolve seasonally migrating regions of RWB. These relative frequencies $\gamma_{a}$ and $\gamma_{c}$ are functions of three independent variables: the year $T$ for $T=1958,1959, \ldots, 2006$; the bin $h=1,2, \ldots, H$; and the starting month $(m=1,2, \ldots, 12)$ of the 2 -month block for which $\gamma$ is calculated. Placing $m$ as a superscript, we can write

$$
\gamma_{a}^{m}(h, T) \equiv \frac{1}{\tau} \sum_{t=1}^{\tau} \Gamma_{a}(h, t, T)
$$

and

$$
\gamma_{c}^{m}(h, T) \equiv \frac{1}{\tau} \sum_{t=1}^{\tau} \Gamma_{c}(h, t, T),
$$

where $\tau$ is the number of 6-hourly observations in the 2-month block, $t$ is time running from the first to the last 6-hourly observation of the 2-month block, the event parameter $\Gamma_{a}$ takes the value 1 when an anticyclonic centroid is located in bin $h$ at time $t$ and zero otherwise, and $\Gamma_{c}$ is likewise for a cyclonic centroid.

Using $\gamma_{a}^{m}(h, T)$ as an example, we define an average across all years and denote it $\bar{\gamma}_{a}^{m}(h)$. We also find the $k$ th EOF and principal component of $\gamma_{a}^{m}(h, T)$, where $k \in\{1,2,3,4\}$ is selected to maximize the correlation between the principal component and a given regressand. The regressand is usually some form of the 

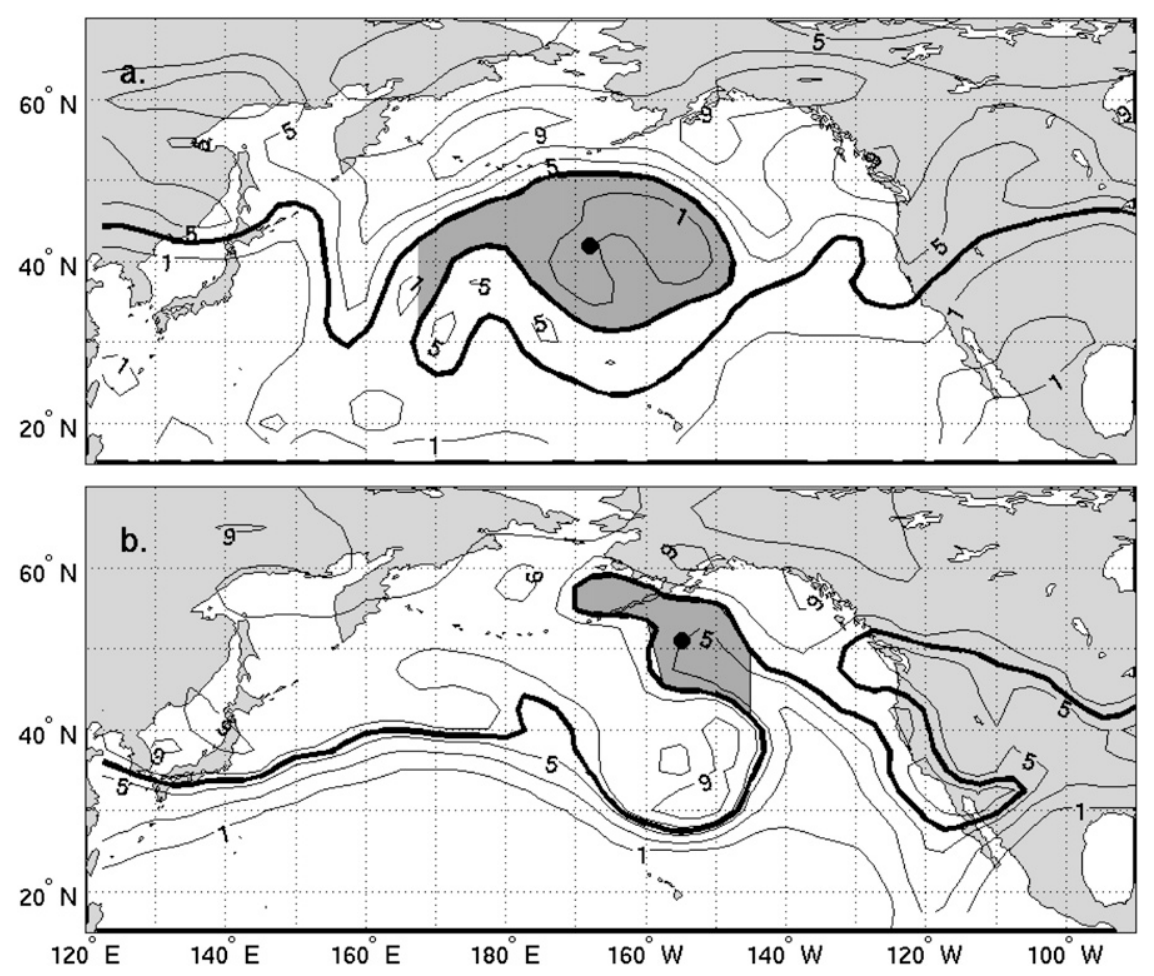

FIG. 2. (a) Anticyclonically overturning PV event at 1200 UTC 8 Jul 1998. 350-K PV is contoured every 2 potential vorticity units ( $\mathrm{pvu} ; 1 \mathrm{pvu}=10^{-6} \mathrm{~m}^{2} \mathrm{~s}^{-1} \mathrm{~K} \mathrm{~kg}^{-1}$ ) with the 3-pvu contour in boldface, the shading shows the area of the poleward tongue and the filled circle marks the tongue's centroid. (b) Same as (a), but for a cyclonic overturning event at 0600 UTC 21 Jan 2006 with the 7-pvu contour in boldface.

PDOI and the most frequently used value of $k$ is 1 . We denote the so-selected $k$ th EOF by $\gamma_{a}^{m}(h)$ and the $k$ th principal component by $\tilde{\gamma}_{a}^{m}(T)$. We will generally omit the explicit dependent variables $h$ and $T$ from the notation from here forward, writing $\gamma_{a}^{m}, \bar{\gamma}_{a}^{m}, \gamma_{a}^{m}$, and $\tilde{\gamma}_{a}^{m}$.

\section{c. Composite analyses}

In section 5, we develop composite views of the atmospheric conditions associated with anticyclonic and cyclonic RWB for various seasons and spatial domains. Each composite includes 200 randomly selected events with a similar spatial scale. Prior to compositing, meteorological fields such as $T$ were converted to anomalies from the time mean, where the time mean is taken over all years while holding fixed the location, observation time, and calendar day. The procedure provides a 1958-2006 time mean specific to, for example, 1200 UTC 1 January at $40^{\circ} \mathrm{N}, 20^{\circ} \mathrm{W}$. To ensure proper alignment of the breaks in the composite, we use an equal-area cylindrical projection that is secant at each centroid, defining a grid of relative latitude and relative longitude with the centroid positioned at the origin. For anticyclonic and cyclonic RWB separately, we use mean $T$, $q$, PV, and $F_{t}$ anomalies to show the break's three- dimensional structure and use mean $u$ and $v$ to show the break's velocity fields at $\sigma=0.995$ and $350 \mathrm{~K}$. Case studies were examined to verify that the composites reflect the salient properties of winter and summer RWB over the Pacific.

\section{d. Statistical methods}

The spatial EOFs $\gamma_{a}^{m}$ and $\gamma_{c}^{m}$ are eigenvectors of the respective covariance matrices of $\gamma_{a}^{m}$ and $\gamma_{c}^{m}$ over the Pacific domain $25^{\circ}-75^{\circ} \mathrm{N}, 150^{\circ} \mathrm{E}-120^{\circ} \mathrm{W}$. No area weighting is necessary because the $\gamma^{m}$ variables are on grid points centered within equal-area bins as described in Strong and Magnusdottir (2008). The EOFs are normalized to unit length and ordered by decreasing eigenvalues. The sign of each EOF is set so that its principal component is positively correlated with the PDOI.

To cross validate a multiple linear regression model, we use a leave-one-out cross-validation scheme and calculated the model's $Q^{2}$ statistic (Wold 1982):

$$
Q^{2}=1-\left\{\sum_{i=1}^{n}\left[y_{i}-\hat{y}_{(i)}\right]^{2} / \sum_{i=1}^{n}\left[y_{i}-\bar{y}_{(i)}\right]^{2}\right\},
$$




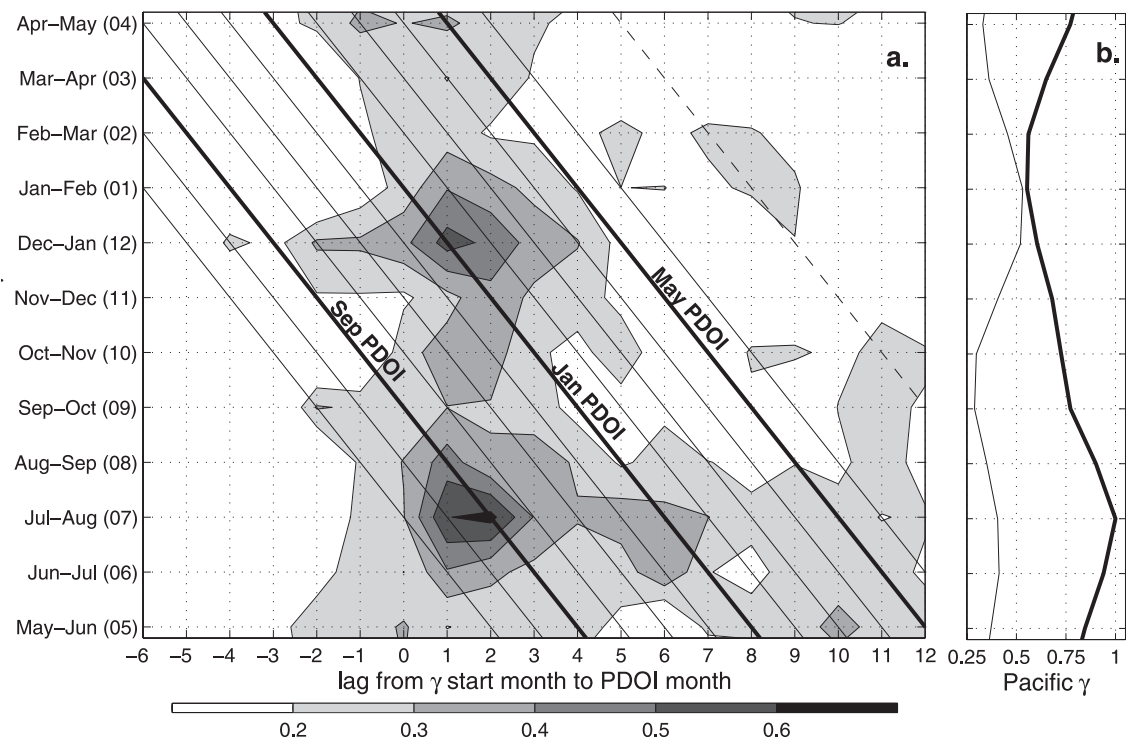

FIG. 3. (a) Percent of PDOI variance accounted for by principal components of anticyclonic and cyclonic RWB at various time lags, and (b) the annual cycles of cyclonic (thin curve) and anticyclonic (boldface curve) Rossby wave breaking over the Pacific. Additional details on each panel are in section 3 .

where $y$ is the regressand, $n$ is the number of observations, a hat denotes a value predicted by the multiple regression model, an overbar denotes the mean, and the notation $(\cdot)_{(i)}$ indicates that the variable is estimated using $n-1$ observations with the $i$ th observation omitted. Here $Q^{2}$ is a jackknife analog of the model coefficient of determination $R^{2}$ and indicates the predictive relevance of the tested model equation. Negative values of $Q^{2}$ indicate that a trivial prediction based on $\bar{y}$ is superior to the fit model, whereas positive values of $Q^{2}$ indicate predictive skill.

\section{Lagged relationships between RWB and PDO}

The purpose of this section is to explore how the PDO and Pacific RWB are correlated at various lags during all months of the year. We define and present the lagged relationships in section $3 \mathrm{a}$ and provide an interpretive discussion of the results in section $3 b$. In section $3 c$, we use the lagged relationships to model the January PDOI as a function of RWB during portions of the immediately preceding winter and summer.

\section{a. Definition of lagged correlations}

To explore the correlation between Pacific RWB and the PDOI at various time lags, we fit a series of multiple linear regression models. In each model, the regressand is the standardized monthly-mean PDOI for a particular month through the record (e.g., each monthly-mean January value for the years 1958-2006), and there are exactly two regressors: $\tilde{\gamma}_{a}^{m}$ and $\tilde{\gamma}_{c}^{m}$. To indicate the lag $(\ell)$ in the model, the PDOI is given a superscript PDOI $^{m+\ell}$ with $\ell=-6,-7, \ldots, 12$, where positive $\ell$ indicates that the $\tilde{\gamma}^{m}$ indices lead the PDOI. As an example, where $m=7$ and $\ell=2$, the September PDOI $\left(\mathrm{PDOI}^{7+2=9}\right)$ is being regressed upon two July-August indices: $\tilde{\gamma}_{a}^{7}$ and $\tilde{\gamma}_{c}^{7}$.

Given the 12 values of $m$ and 19 values of $\ell$, we have 228 linear regression models of the form

$$
\mathrm{PDOI}^{m+\ell}=\beta_{1} \tilde{\gamma}_{a}^{m}+\beta_{2} \tilde{\gamma}_{c}^{m}+\varepsilon,
$$

where $\beta_{1,2}(m, \ell)$ are regression coefficients and $\varepsilon$ are random errors. The principal component $k \in\{1,2,3,4\}$ selected for each of the $\tilde{\gamma}^{m}$ indices was determined by the method of exhaustive search, and was most frequently the leading EOF of each (i.e., $k=1$ ). The $R^{2}$

TABLE 1. Table of Pearson correlation coefficients with results significant under bootstrapping shown in boldface. The $\tilde{\gamma}$ variables are indices of Rossby wave breaking, PDOI $\mathrm{Jan}_{\mathrm{n}}$ is the January PDOI, MEI is the multivariate ENSO index, NAMI is the northern annular mode index, and PNAI is the Pacific-North American pattern index. The MEI, NAMI, and PNAI are contemporaneous with the $\tilde{\gamma}^{12}$ indices, meaning they follow the $\tilde{\gamma}^{7}$ indices by 5 months.

\begin{tabular}{lrrcc}
\hline \hline & MEI & NAMI & PNAI & PDOI $_{\text {Jan }}$ \\
\hline$\tilde{\gamma}_{a}^{12}$ & $\mathbf{0 . 3 5}$ & $-\mathbf{0 . 4 3}$ & 0.20 & $\mathbf{0 . 4 1}$ \\
$\tilde{\gamma}_{c}^{12}$ & $\mathbf{0 . 2 8}$ & $-\mathbf{0 . 4 2}$ & $\mathbf{0 . 7 6}$ & $\mathbf{0 . 6 9}$ \\
$\tilde{\gamma}_{a}^{7}$ & $\mathbf{0 . 3 9}$ & 0.06 & $\mathbf{0 . 2 9}$ & $\mathbf{0 . 4 5}$ \\
$\tilde{\gamma}_{c}^{7}$ & -0.01 & 0.19 & $\mathbf{0 . 4 8}$ & $\mathbf{0 . 4 2}$ \\
\hline
\end{tabular}




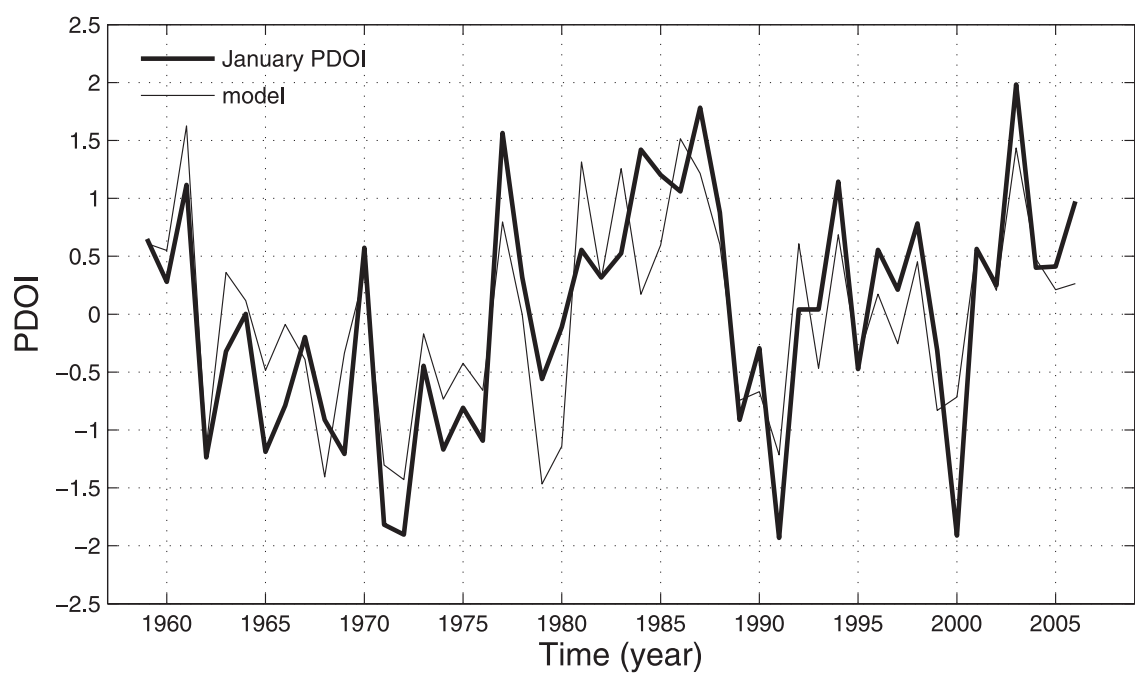

FIG. 4. The January PDOI and a statistical model constructed from four principal components of Rossby wave breaking. Additional details are in section 3 .

values for the 228 individually fit models are contoured in Fig. 3a, with the first level of shading indicating that a particular model's $R^{2}$ is at least 0.2 and its $F$ statistic is significant at the $95 \%$ confidence level.

Values along the abscissa correspond to $\ell$ and the ordinate shows the two months used to calculate the $\tilde{\gamma}^{m}$ indices (i.e., the months $m$ and $m+1$, where $m$ is shown in parentheses). The 2-month labels cycle up the ordinate from May-June at the bottom $(m=5)$ to April-May $(m=4)$ at the top to facilitate upcoming discussion of the results in the context of the typical ENSO cycle in which El Niño-related SST anomalies emerge in summer, peak in winter, and persist through the subsequent spring. Normalized annual cycles of Pacific anticyclonic and cyclonic RWB are shown in Fig. $3 \mathrm{~b}$ for reference (i.e., $\bar{\gamma}_{a}^{m}$ and $\bar{\gamma}_{c}^{m}$ averaged over the domain in Fig. 2 and normalized by the maximum of the anticyclonic time series).

Lines where the PDOI month being predicted remains constant run from the upper left to lower right of Fig. 3a (September, January, and May PDOI lines are labeled). Since each of the twelve diagonal lines crosses at least one shaded region, it is possible to use two EOFbased RWB indices $\left(\tilde{\gamma}_{a}^{m}\right.$ and $\left.\tilde{\gamma}_{c}^{m}\right)$ to form a significant model of any one monthly-mean PDOI time series. ${ }^{1}$

\section{b. Interpretation of lagged correlations}

Summer RWB during July-August appears to have a persistent effect on the PDOI through the ensuing ENSO cycle (shading from lags 0-11 for the July-August

\footnotetext{
${ }^{1}$ To consider significance in modeling more than one monthly mean PDOI time series, we would need to consider issues of hypothesis multiplicity or stack and solve the models simultaneously.
}

period, Fig. 3a). Summer anticyclonic RWB can strongly impact heat exchange at the air-sea interface because anticyclonic RWB is reaching its peak frequency during July-August (Fig. 3b) and, as we will show in section 4 , the breaking advection patterns advect the summer season's warm, moist tropical air poleward. The August-October breaking cycle is less important to the PDOI because Pacific $\bar{\gamma}_{a}, \bar{\gamma}_{c}$, and tropical air temperatures are beginning to decline. The importance of breaking to the PDOI increases during October-February (Fig. 3a) as cyclonic breaking reaches its annual peak (Fig. 3b) and the pool of cold dry air potentially advected by cyclonic breaking builds over the higher latitudes. The importance of FebruaryMarch breaking is diminished as cyclonic RWB frequency declines, anticyclonic RWB frequency is near its minimum, and the cold dry pool is weakening.

The March-May pattern of breaking is important to the PDOI largely because $\bar{\gamma}_{a}$ is beginning to increase, but these months have a limited window in which to impact the PDOI since the ENSO cycle is concluding. Once the ocean-atmosphere system enters into another ENSO cycle (to the right of the May PDOI line in Fig. 3a), the PDOI appears less sensitive to RWB in the previous ENSO cycle (i.e., there are fewer shaded regions, meaning fewer significant RWB-based models of the PDOI). An exception is for the September PDOI, which is the regressand for models along the dashed line toward the upper right of Fig. 3a. The patches of shading along this dashed September PDOI line may be indicative of the SST reemergence phenomenon (Alexander et al. 1999) wherein late-winter/early-spring SST anomalies in the deep ocean mixed layer are isolated from the 

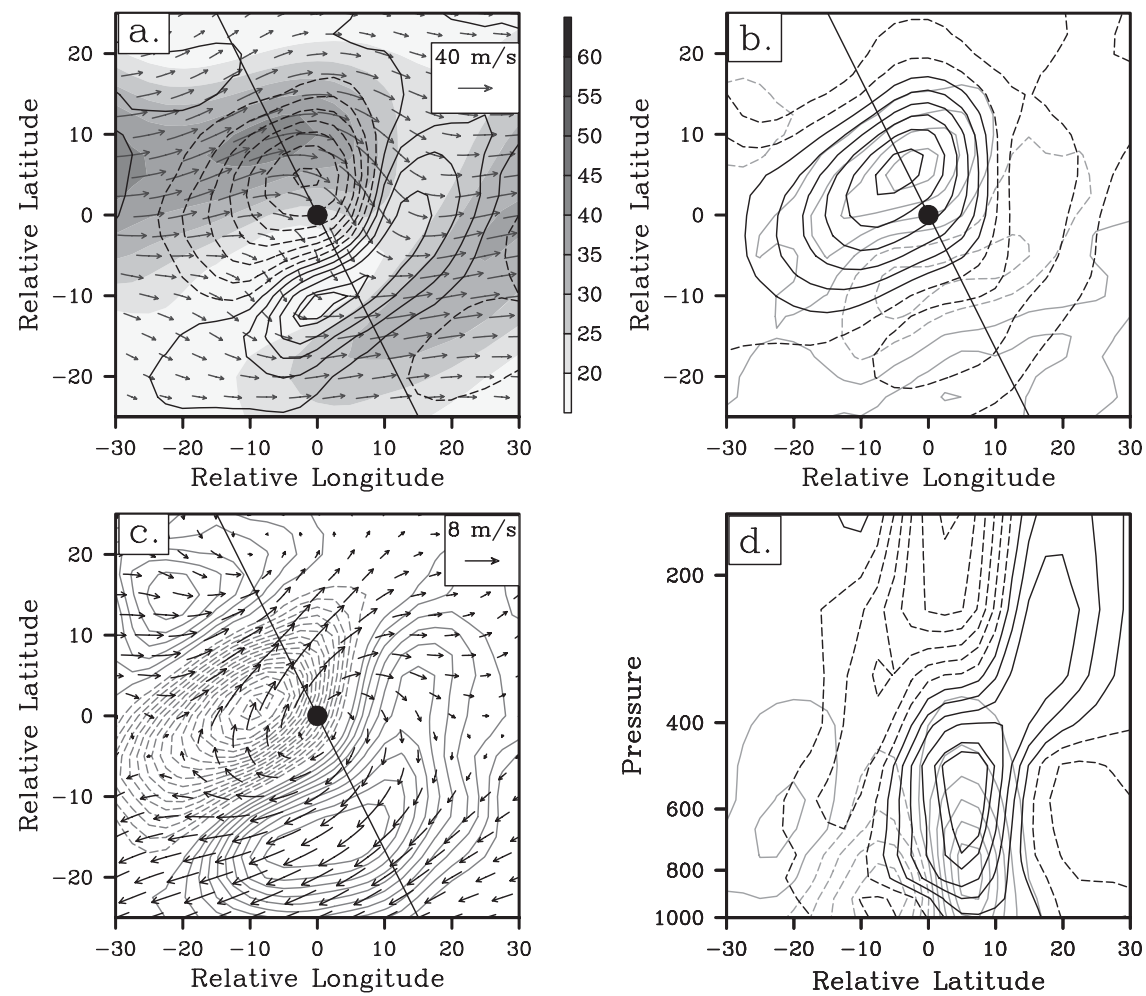

FIG. 5. Composite of 200 randomly selected December-January anticyclonic RWB events occurring within the domain $25^{\circ}-55^{\circ} \mathrm{N}, 150^{\circ} \mathrm{E}-120^{\circ} \mathrm{W}$ from 1958 to 2006 . Negative contours are dashed and the zero contour is suppressed throughout. (a) At $350 \mathrm{~K}$ : wind velocity (arrows), wind speed (shading), and anomalies of PV (contours every $0.3 \mathrm{pvu}$ ). (b) At $500 \mathrm{hPa}$ : anomalies of $T$ (dark contours every $0.8 \mathrm{~K}$ ) and $q$ (light contours every $1.5 \times 10^{-4}$ ). (c) Near-surface wind velocity (arrows) and anomalies of surface turbulent heat flux $\left(F_{t}\right.$, contours every $\left.5 \mathrm{~W} \mathrm{~m}^{-2}\right)$. (d) For the cross section through the line in (a), (b), and (c) viewed from the east; anomalies of $T$ and $q$ contoured as in (b).

atmosphere in the summer and then reemerge when the mixed layer deepens during the following fall/winter.

\section{c. Linear regression model of January PDOI}

The importance of the ENSO cycle as a temporal frame for investigating the linkage between RWB and the PDO is clear from the above-noted drop off in $R^{2}$ where the predicted PDOI is in the next ENSO cycle. We thus select the January PDOI (denoted PDOI Jan $_{\text {an }}$ ) as an interesting example of the RWB-PDO relationship because January has the imprint of the important latesummer and early-winter breaking periods without the confounding effects of the late-spring-early-summer transition into another ENSO cycle. In this section, we examine the relationship between $\mathrm{PDOI}_{\mathrm{Jan}}$ and RWB during the immediately preceding December-January and July-August months by fitting a linear regression model of the form

$$
\mathrm{PDOI}_{\mathrm{Jan}}=\beta_{1} \tilde{\gamma}_{a}^{12}+\beta_{2} \tilde{\gamma}_{c}^{12}+\beta_{3} \tilde{\gamma}_{a}^{7}+\beta_{4} \tilde{\gamma}_{c}^{7}+\varepsilon .
$$

The $\gamma$ terms on the right-hand side are all leading principal components, and each is significantly correlated with the regressand PDOI Jan under bootstrapping (Table 1, right column).

To ensure that we do not overfit the model in Eq. (5), we performed a bootstrapped backward stepwise regression using the Akaike information criterion (AIC) and used only the regressors that were retained in at least $60 \%$ of the 1000 resampled iterations-a procedure shown to produce parsimonious models with excellent predictive capability (Austin and Tu 2004). There are no significant correlations among the regressors, and each regressor was retained in more than $90 \%$ of the iterations. For standardized regressors and regressand, the least squares fit has coefficients $\beta_{1,2,3,4}=[0.28,0.51,0.22,0.29]$ and is shown in Fig. 4. This model's $R^{2}$ is 0.69 meaning that it accounts for more than two-thirds of the PDOI $\mathrm{Jan}_{\text {variability, and its }}$ overall $F$ statistic is significant at the $95 \%$ confidence level. Cross validating the model, we find $Q^{2}=0.59$ 

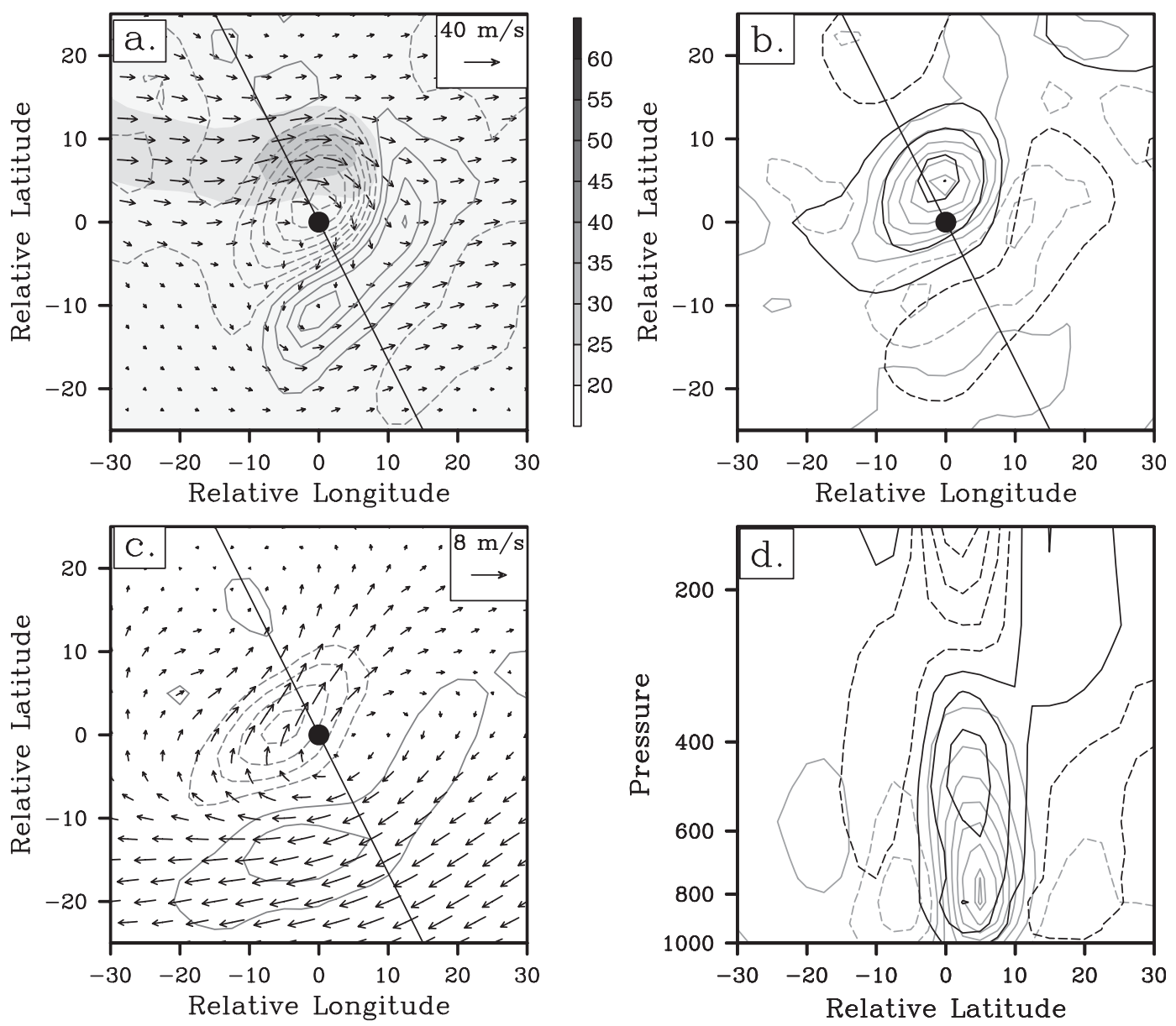

FIG. 6. As in Fig. 5, but for July-August.

(defined in section 2d), which is positive and not alarmingly different from the model $R^{2}$.

\section{Composite analyses}

The preceding, primarily statistical analysis motivates an investigation of the physical role that RWB plays in generating the SST anomaly patterns associated with the PDO. In this section we use the composite analysis method described in section $2 \mathrm{c}$ to determine and visualize the coherent three-dimensional structure of anticyclonic and cyclonic RWB. Our aim is to illustrate how these coherent structures contribute to the SST anomaly patterns of the PDO by organizing patterns of turbulent heat flux at the air-sea interface.

\section{a. Anticyclonic}

During December and January over the Pacific basin, anticyclonic wave breaking generally occurs on the anticyclonic flank of the eddy-driven jet, as evidenced by the surrounding composite velocity field (Fig. 5a), and is associated with poleward (equatorward) advection of a low-PV (high PV) tongue as shown by the composite PV anomalies in Fig. 5a. The low-PV (high PV) tongue is the upper-tropospheric signature of an anomalously warm and moist (cool and dry) column that extends to the surface (Figs. 5b,d). The nearly vertical alignment of the $T, q$, and PV anomalies can be seen by comparing Figs. 5a and 5b, and the depth of the $T$ and $q$ anomalies are shown in cross section in Fig. 5d. Below the negative vorticity advection near the composite centroid in Fig. 5 a $\left(0^{\circ}\right.$ relative latitude $0^{\circ}$ relative longitude), positive $\omega$ (not shown) supports a divergent anticyclonic surface circulation (Fig. 5c). The column of air advected to the southeast of the surface anticyclone is anomalously cool and dry (Figs. 5b,d), contributing to positive $F_{t}$ anomalies (Fig. 5c), and the column of air advected to the northwest of the surface anticyclone is anomalously warm and moist (Figs. 5b,d), contributing to negative $F_{t}$ anomalies (Fig. 5c). 

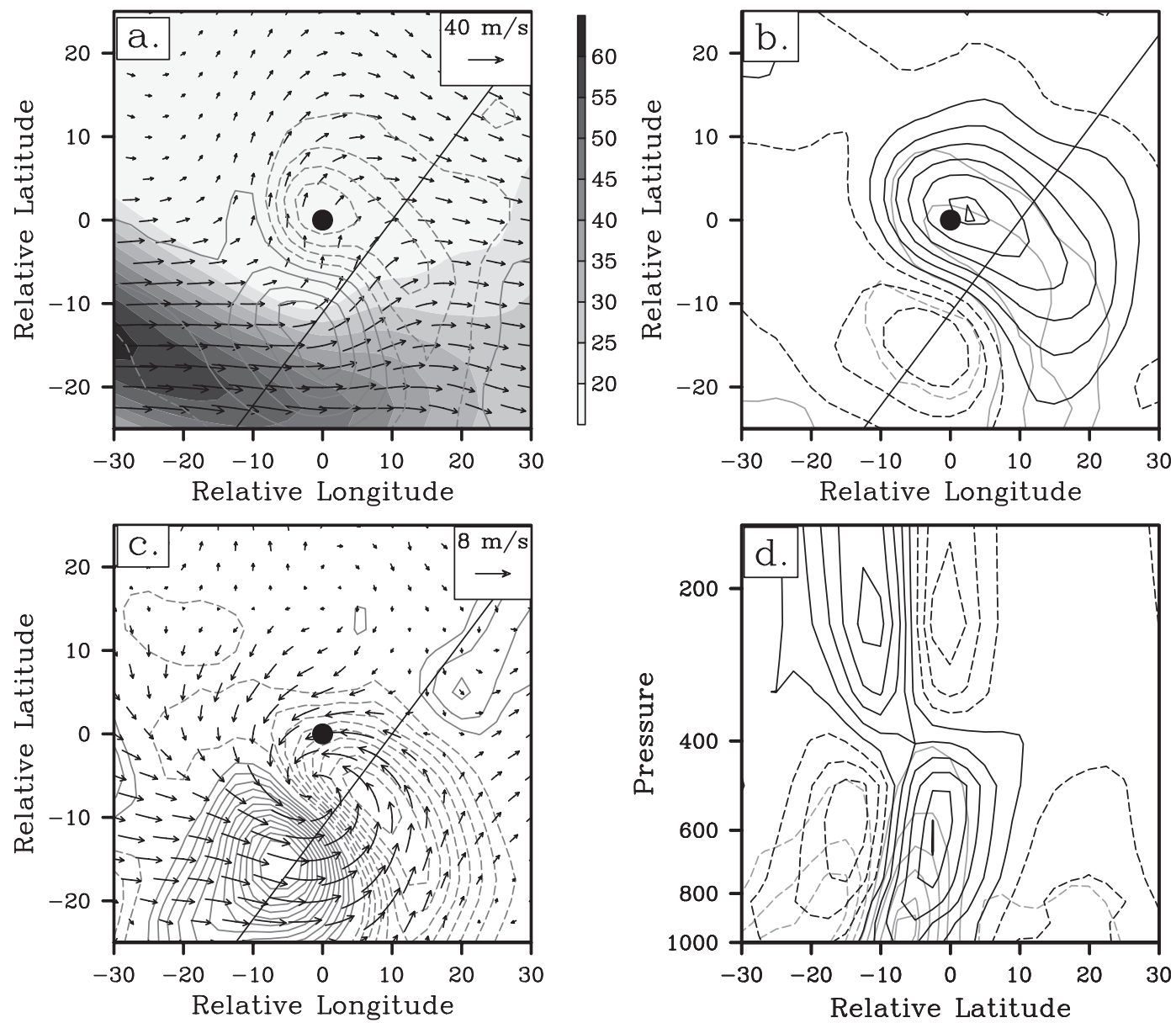

FIG. 7. As in Fig. 5, but for 200 randomly selected December-January cyclonic RWB events occurring within the domain $45^{\circ}-65^{\circ} \mathrm{N}, 150^{\circ} \mathrm{E}-120^{\circ} \mathrm{W}$.

During July-August, the eddy-driven jet on the poleward flank of the anticyclonically breaking waves is weaker (Fig. 6a), and reduced temperature gradients support low-PV tongue temperature anomalies approximately one-half the magnitude of those seen in the winter composite (cf. Figs. 5b and 6b). The $F_{t}$ anomalies are also weaker in the summer composite (Fig. 6c), particularly below the high-PV tongue whose column of negative temperature anomalies fails to reach the surface (near $-10^{\circ}$ relative latitude, Fig. $6 \mathrm{~d}$ ). Despite the relative weakness of its surface flux signature, summer anticyclonic RWB has a marked impact on the PDO because, as we will show in section 5 , it occurs more frequently than its winter counterpart.

\section{b. Cyclonic}

December-January cyclonic RWB over the Pacific basin occurs on the cyclonic flank of the eddy-driven jet (Fig. 7a) and features a warm, moist (cool, dry) column below the low-PV (high PV) tongue that extends to the surface (Figs. 7b,d). The positive vorticity advection near $-5^{\circ}$ relative latitude indicates upward vertical motion (not shown) and a surface cyclonic circulation (Fig. 7c). Advection of cool, dry (warm, moist) air to the southwest (east) of the cyclonic center supports positive (negative) $F_{t}$ anomalies (Fig. 7c). The July-August cyclonic RWB composite (Fig. 8) is similar to the December-January composite. The tongues are somewhat smaller (Figs. $8 \mathrm{a}, \mathrm{b}, \mathrm{d})$ but are associated with comparable $F_{t}$ anomalies at the surface (Fig. 8c).

\section{Regions where RWB influences the PDO}

In the preceding sections, we showed that 1) RWB is a spatially coherent three-dimensional phenomenon that connects upper-tropospheric PV dynamics to patterns of surface-layer advection and turbulent heat flux (section 4), and 2) principal components derived from spatial EOFs of RWB are efficacious regressors for modeling the PDOI (section 3). This section uses the physical results in section 4 to explain the statistical results in 

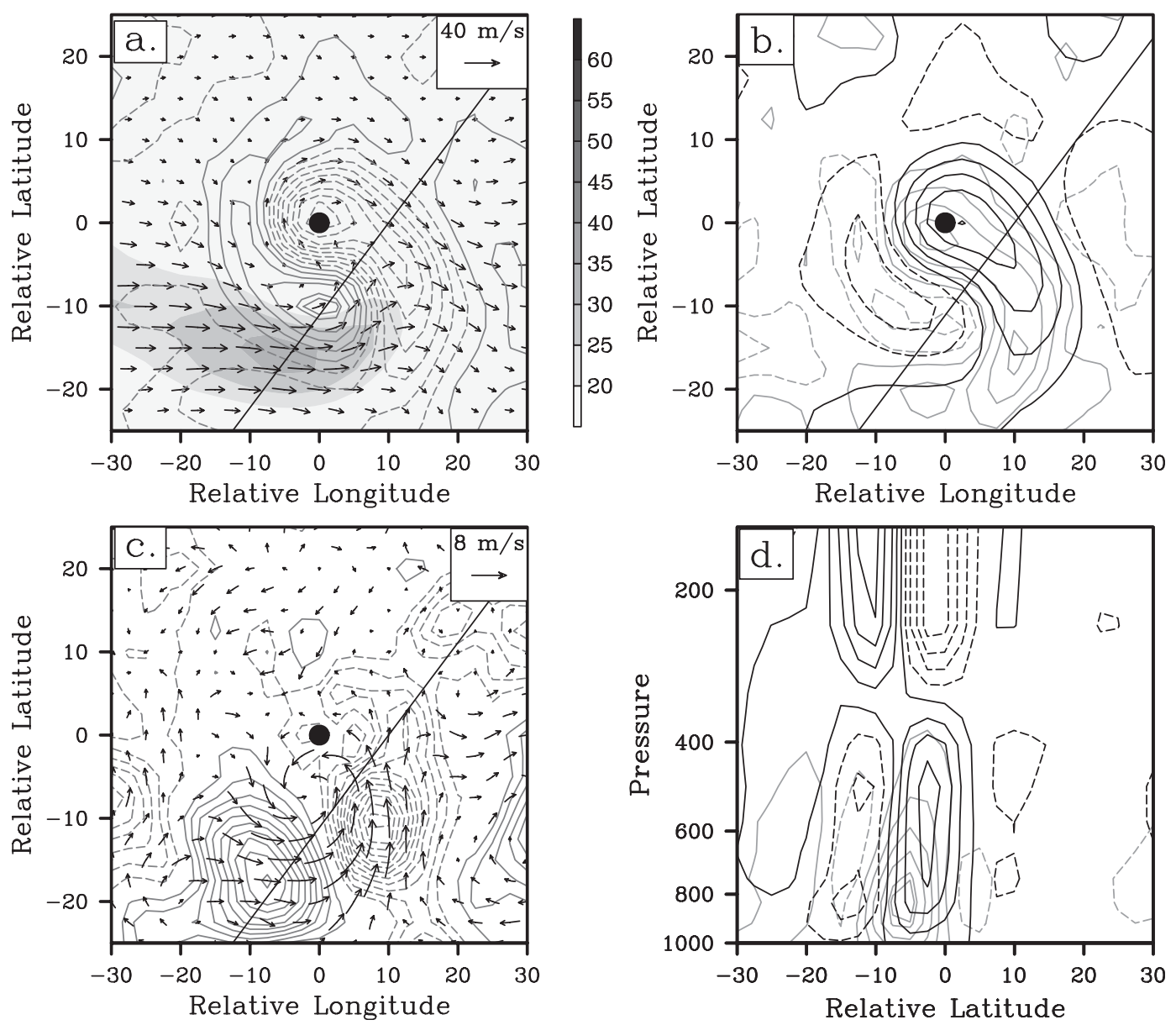

FIG. 8. As in Fig. 5, but for 200 randomly selected July-August cyclonic RWB events occurring within the domain $45^{\circ}-65^{\circ} \mathrm{N}, 150^{\circ} \mathrm{E}-120^{\circ} \mathrm{W}$.

section 3. We begin by identifying the regions where RWB most strongly influences the PDO by examining the leading EOFs that generated the four regressors of PDOI $\mathrm{Jan}_{\mathrm{an}}: \boldsymbol{\gamma}_{a}^{12}, \boldsymbol{\gamma}_{c}^{12}, \boldsymbol{\gamma}_{a}^{7}$, and $\boldsymbol{\gamma}_{c}^{7}$. We then show that placement of cyclonic or anticyclonic centroids near the centers of action of these EOFs produces surface wind and turbulent heat flux anomaly patterns consistent with the composite views in section 4, and that these RWBrelated surface flux anomalies project onto the spatial pattern of the PDO.

\section{a. December-January anticyclonic $R W B$ regions}

During December and January, anticyclonic RWB is organized into a well-defined region of frequent breaking called a "surf zone" and marked by the regionally dark $\bar{\gamma}_{a}^{12}$ shading in Fig. 9a. The leading pattern of anticyclonic RWB variability over the Pacific $\left(\gamma_{a}^{12}\right)$ is contoured in Fig. 9a and captures interannual variability in the westward extent of the Pacific surf zone. When the associated principal component $\left(\tilde{\gamma}_{a}^{12}\right)$ is large and negative, there is an anomalously high frequency of anticyclonic RWB occurring over the east Pacific negative center of action and the PDOI $I_{\mathrm{Jan}}$ tends to be anomalously low (recall that the sign of EOFs are set so that the associated principal component is positively correlated with the PDOI). The tendency for anomalously low PDOI $\mathrm{Jan}_{\text {to }}$ associate with anomalously frequent anticyclonic RWB over the east Pacific follows from the significant positive correlation $r\left(\mathrm{PDOI}_{\mathrm{Jan}}, \tilde{\gamma}_{a}^{12}\right)=0.41$ (Table 1) and the primarily negative covariance field $\operatorname{cov}\left(\mathrm{PDOI}_{\mathrm{Jan}}, \tilde{\gamma}_{a}^{12}\right)$ in Fig. $9 \mathrm{~b}$.

To illustrate why anomalously frequent anticyclonic RWB over this east Pacific region projects negatively onto the spatial pattern of the PDO, we develop a composite map of the surface wind and turbulent heat flux anomalies corresponding to times when an anticyclonic centroid was observed within a radius $\alpha$ of the location where $\gamma_{a}^{12}$ and $\operatorname{cov}\left(\mathrm{PDOI}_{\mathrm{Jan}}, \tilde{\gamma}_{\mathrm{a}}^{12}\right)$ are both large and of like sign. This location is marked by the filled circle in Fig. $9 \mathrm{~b}$ and corresponds to the local maximum of the field 

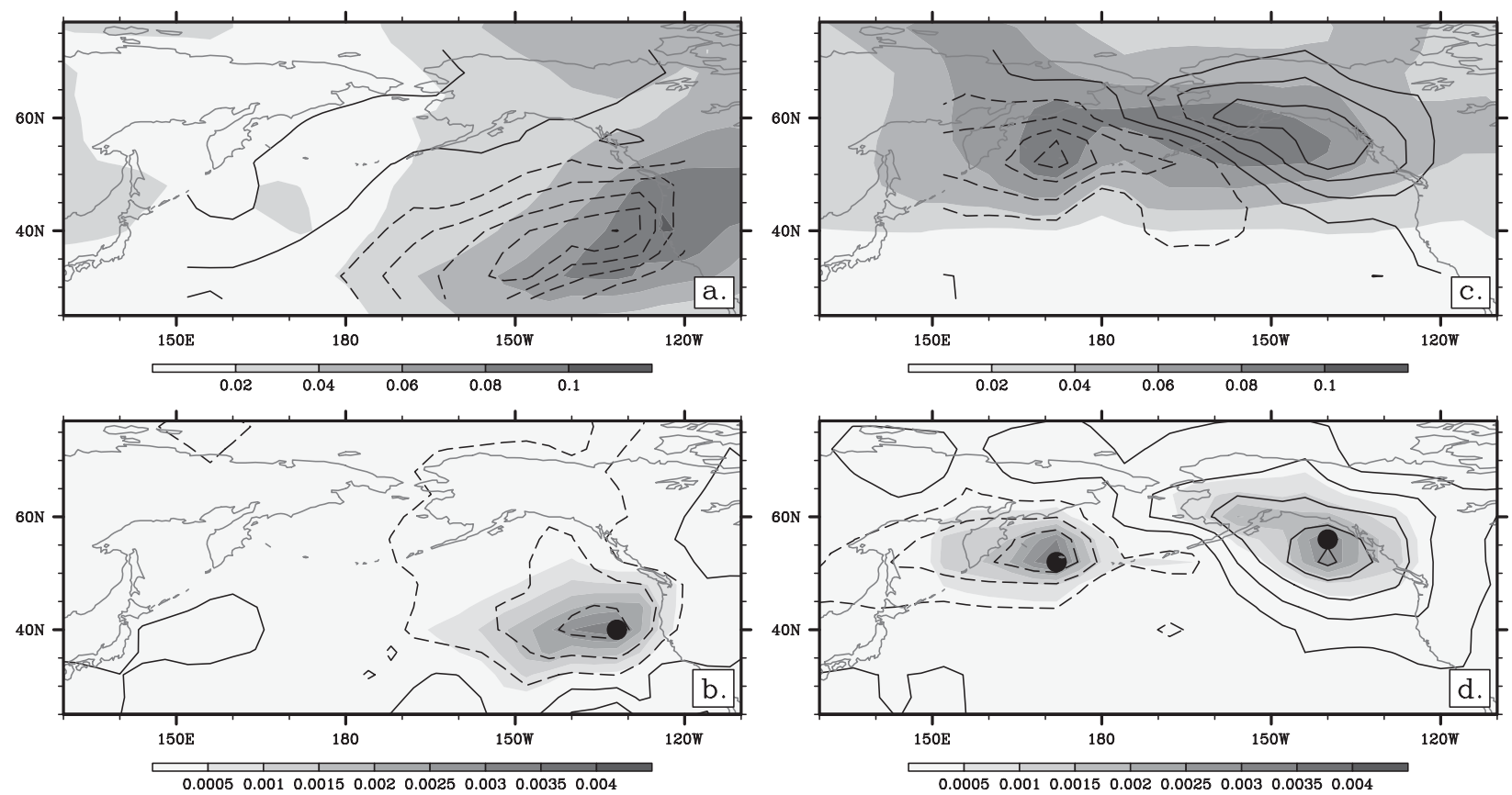

FIG. 9. For December-January 1958-2006: (a) the mean relative frequency of anticyclonic RWB ( $\bar{\gamma}_{a}^{12}$, shading) and the leading EOF of anticyclonic RWB ( $\gamma_{a}^{12}$, contoured at 0.04 with negative values dashed). (b) $L$ [defined in Eq. (6), shaded] and the covariance between the PDOI and $\gamma_{a}^{12}$, (contoured at 0.005 with negative values dashed). (c), (d) As in (a) and (b), but for $\gamma_{c}^{12}$.

$$
L_{a}^{m}(h) \equiv \max \left[0, \gamma_{a}^{m} \cdot \operatorname{cov}\left(\mathrm{PDOI}_{\mathrm{Jan}}, \tilde{\gamma}_{a}^{m}\right)\right],
$$

where $m=12$ and the dot indicates entry-wise product of two spatial fields ( $L_{a}^{12}$ is shaded in Fig. 9b). We use $\alpha=340$ $\mathrm{km}$ for this and all subsequent composite analyses, which gives a sample size of at least 300 for each composite.

The composite surface field anomaly map for times with an anticyclonic centroid near the east Pacific $L_{a}^{12}$ local maximum is shown in Fig. 10a. The surface circulation and flux patterns closely resemble those shown in the composite in section $4 \mathrm{a}$ and align with the PDO warm and cool regions so as to lower the PDOI $\mathrm{Jan}_{\text {. The }}$ longitudinal shift in the anticyclonic surf zone captured by $\tilde{\gamma}_{a}^{12}$ is related to ENSO and also the NAM (Table 1) as explained in Abatzoglou and Magnusdottir (2006) and Strong and Magnusdottir (2008), respectively.

\section{b. December-January cyclonic RWB regions}

The leading pattern of variability associated with the winter cyclonic surf zone over the Pacific $\left(\boldsymbol{\gamma}_{c}^{12}\right)$ is contoured in Fig. $9 \mathrm{c}$ and captures a longitudinal migration of the region of frequent cyclonic RWB. When the associated principal component $\left(\tilde{\gamma}_{c}^{12}\right)$ is large and positive, the cyclonic surf zone is shifted eastward, meaning anomalously frequent (infrequent) cyclonic RWB near the positive (negative) center of action. The significant positive correlation $r\left(\mathrm{PDOI}_{\mathrm{Jan}}, \tilde{\gamma}_{c}^{12}\right)=0.69$ (Table 1) and the mapped covariance field $\operatorname{cov}\left(\mathrm{PDOI}_{\mathrm{Jan}}, \tilde{\gamma}_{\mathrm{c}}^{12}\right)$ (Fig. 9d) indicate that anomalously high values of $\mathrm{PDOI}_{\mathrm{Jan}}$ tend to be associated with an eastward-shifted cyclonic surf zone.

We use the cyclonic analog of Eq. (6) with $m=12$ $\left(L_{c}^{12}\right.$, shaded in Fig. 9d) to locate two regions where $\boldsymbol{\gamma}_{c}^{12}$ and $\operatorname{cov}\left(\mathrm{PDOI}_{\mathrm{Jan}}, \tilde{\gamma}_{\mathrm{c}}^{12}\right)$ are both large and of like sign (filled circles, Fig. 9d). When cyclonic RWB occurs near the $L_{c}^{12}$ local maximum over the northwest Pacific, there is an associated surface cyclonic circulation situated to the southwest of the centroid, just as in the more general composite developed for the entire Pacific domain (cf. Figs. $10 \mathrm{~b}$ and $7 \mathrm{c}$ ). This cyclonic circulation advects anomalously warm and moist air up its southeastern flank, generating anomalously downward heat flux over the PDO cool region.

Cyclonic RWB near the northeast Pacific $L_{c}^{12}$ local maximum supports a cyclonic surface circulation (Fig. 10c), whose associated flux anomalies are strikingly well aligned with the PDO cool and warm regions so as to increase the $\mathrm{PDOI}_{\mathrm{Jan}}$. The longitudinal shift in the cyclonic surf zone captured by $\tilde{\gamma}_{c}^{12}$ is related to the ENSO and NAM, and strongly tied to the PNA as shown by the correlations in the second row of Table 1.

\section{c. July-August anticyclonic RWB regions}

The winter-to-summer weakening of the Pacific jet stream is accompanied by a westward shift and intensification of the anticyclonic surf zone (cf. Figs. 11a and 9a). The 

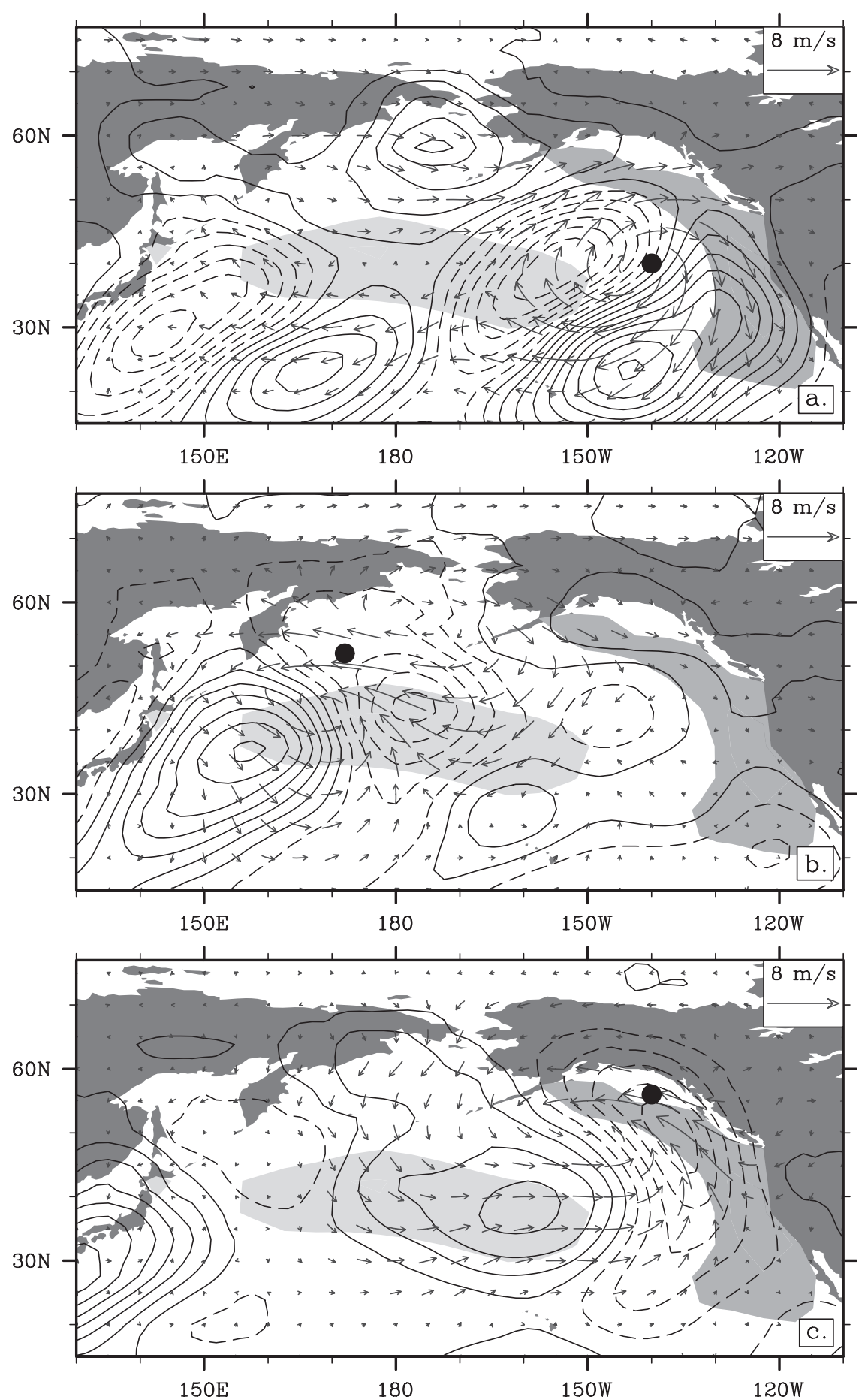

FIG. 10. Composite surface turbulent heat flux $\left(F_{t}\right)$ and surface velocity for all DecemberJanuary observation times when the region within $340 \mathrm{~km}$ of the filled circle contained (a) an anticyclonic centroid and (b), (c) a cyclonic centroid. Contouring is every $4 \mathrm{Wm}^{-2}$ with negative values dashed, and the shaded "PDO cool" and "PDO warm" regions are repeated from Fig. 1. 

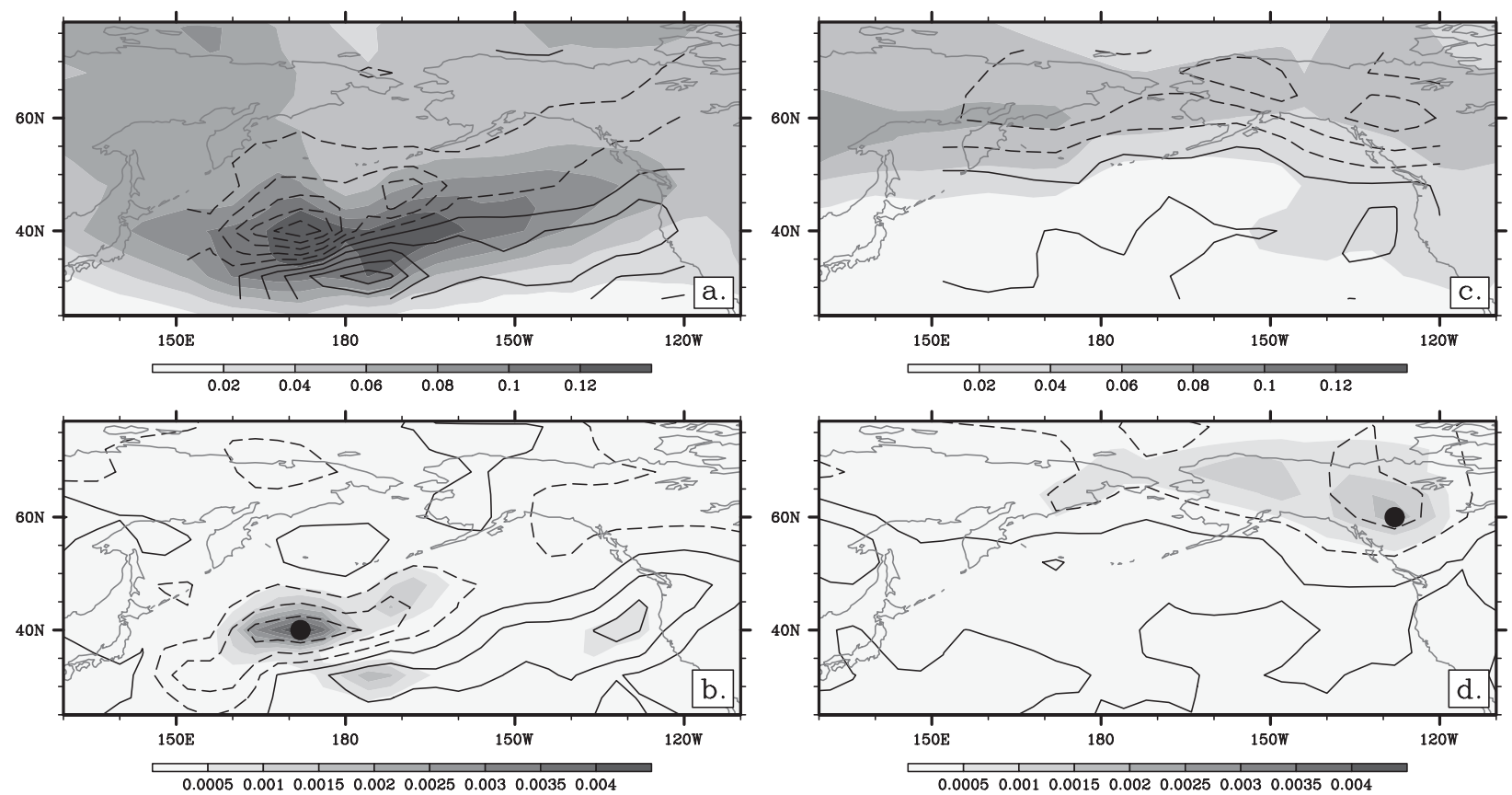

FIG. 11. Same as Fig. 9, but for July-August.

associated leading pattern of variability $\left(\boldsymbol{\gamma}_{a}^{7}\right.$, Fig. 11a) captures an anticyclonic rotation of the surf zone's two local maxima about a point near $40^{\circ} \mathrm{N}, 180^{\circ}$. When the associated principal component $\left(\tilde{\gamma}_{a}^{7}\right)$ is large and negative, anticyclonic RWB is anomalously frequent over the negative center of action near $40^{\circ} \mathrm{N}, 170^{\circ} \mathrm{E}$. The covariance field $\operatorname{cov}\left(\mathrm{PDOI}_{\mathrm{Jan}}, \tilde{\gamma}_{\mathrm{a}}^{7}\right)$ (Fig. 11b) indicates that anomalously low values of $\mathrm{PDOI}_{\mathrm{Jan}}$ tend to be associated with increased anticyclonic RWB over the negative center of action whereas the response of the PDOI to the positive center of action is relatively weak. The significant correlation $r\left(\mathrm{PDOI}_{\mathrm{Jan}}, \tilde{\gamma}_{a}^{7}\right)=0.45(\mathrm{Ta}-$ ble 1 ) is thus primarily related to anticyclonic RWB near the region marked by a filled circle in Fig. 11b, which corresponds to the largest local maximum of $L_{a}^{7}$ (shading, Fig. 11b).

Anticyclonic RWB over the west Pacific near the absolute maximum of $L_{a}^{7}$ generates a surface anticyclonic circulation and flux anomaly pattern that would tend to lower the PDOI since downward heat flux anomalies align with the PDO cool region (Fig. 12a). The $L_{a}^{7}$ maximum occurs near the western edge of the anticyclonic surf zone, so many of the centroids detected in this region mark waves that are just starting to overturn and may progress $1000 \mathrm{~km}$ or farther downstream before becoming quasi-stationary and mixing out their PV gradients. Such eastward translation of the anticyclonic composite surface field would move the region of anomalously downward heat flux across a larger portion of the PDO cool region. The slight northwest-to-southeast tilt of the PDO cool region (light shading, Fig. 12a) is especially interesting given the tendency for anticyclonically breaking waves to move southeastward away from the jet stream as they become quasi-stationary.

\section{d. July-August cyclonic $R W B$ regions}

The summer cyclonic surf zone is not as well-defined as its winter counterpart and the associated leading EOF is diffuse (Fig. 9c). Low values of the corresponding principal component $\left(\tilde{\gamma}_{c}^{7}\right)$ are associated with anomalously frequent cyclonic RWB over Alaska and western Canada. The covariance field $\operatorname{cov}\left(\mathrm{PDOI}_{\mathrm{Jan}}, \tilde{\gamma}_{\mathrm{c}}^{7}\right)$ (Fig. 11d) indicates that the strongest association is in northwest Canada, and the local maximum of $L_{c}^{7}$ is indicated by filled circle in Fig. 11d. Cyclonic RWB over northwest Canada generates anomalously upward heat flux over the PDO warm region (Fig. 12b) which would be conducive to anomalously low PDOI $_{\text {Jan }}$ in accordance with the sign of the correlation $r\left(\mathrm{PDOI}_{\mathrm{Jan}}, \tilde{\gamma}_{c}^{7}\right)=0.42($ Table 1$)$.

\section{Summary and discussion}

We presented evidence in support of the hypothesis that RWB variability is the physical mechanism by which ENSOand PNA-related changes in the background flow project surface heat flux anomalies onto the spatial pattern of the PDO. Leading patterns of cyclonic and anticyclonic RWB variability can be used to account for a significant fraction of 

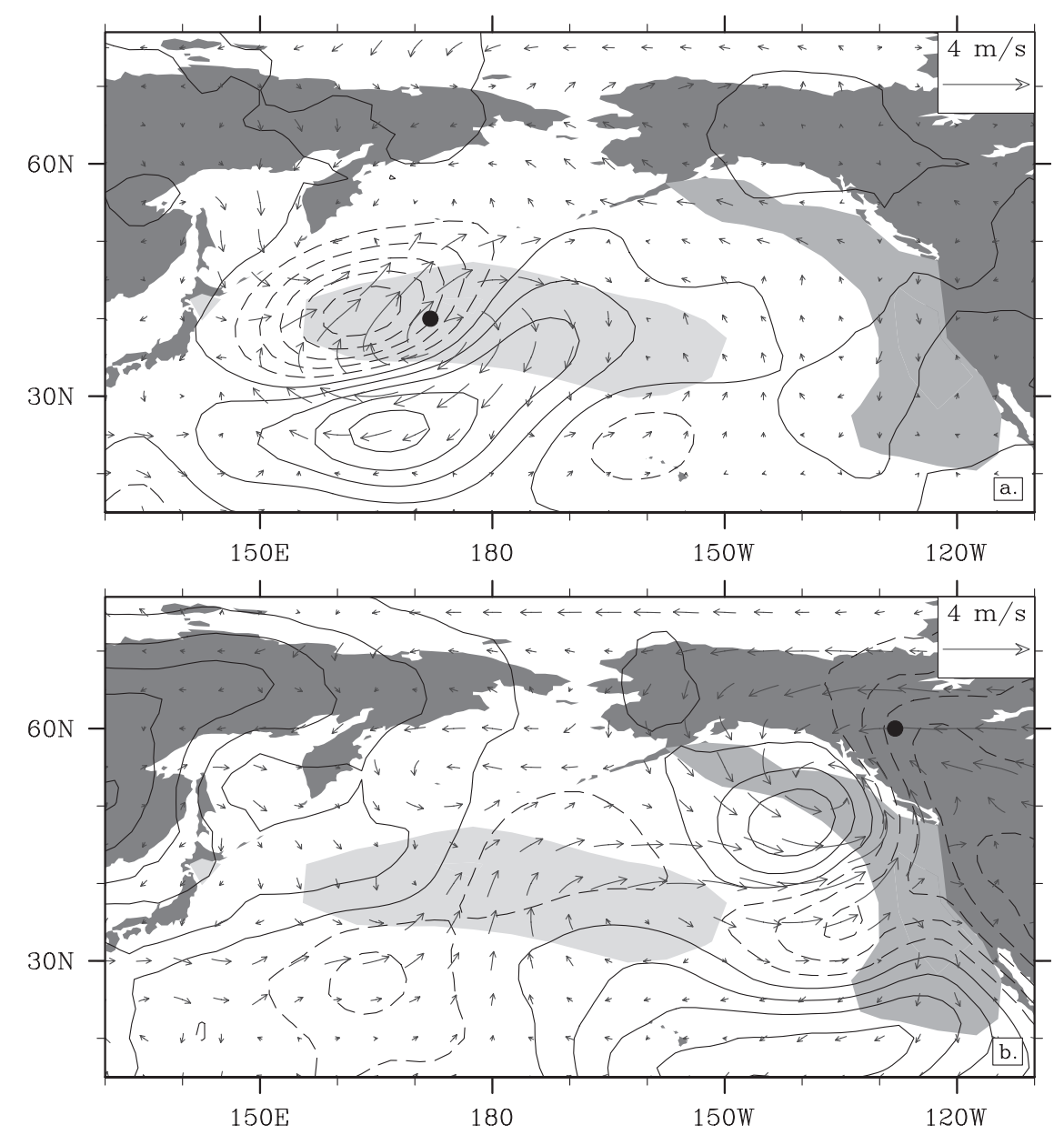

FIG. 12. Same as Fig. 10, but for July-August observation times when the region within $340 \mathrm{~km}$ of the filled circle contained (a) an anticyclonic centroid and (b) a cyclonic centroid.

the PDOI for any month of the year, and four EOF-based RWB indices from July to August and December to January account for more than two-thirds of the January mean PDOI for 1958-2006. Composite analyses based on hundreds of RWB cases illustrated that anticyclonic (cyclonic) RWB is associated with a warm, moist (cool, dry) column that extends down to a surface anticyclonic (cyclonic) circulation, and that the moisture and temperature advection associated with the surface circulation patterns force coherent patterns of surface turbulent heat flux that project onto the spatial pattern of the PDO. In regions where RWB variability affects the PDO, the relative frequency of RWB is related to ENSO and the leading two patterns of internal atmospheric variability: the NAM and PNA. The results explain the free troposphereto-surface segment of the atmospheric bridge concept wherein El Niño anomalies emerge in summer and modify circulation patterns that act over several months to force sea surface temperature (SST) anomalies in the extratropical Pacific during late winter or early spring.
Much progress has been made by previous research investigating the PDO in the context of the atmospheric bridge from El Niño to extratropical Pacific SSTs, with an emphasis on shifts in the position or strength of storm tracks, often summarized using the climatological feature of the Aleutian low (e.g., Schneider and Cornuelle 2005). Our analysis of RWB relative frequency provides a view of the Pacific jet stream and storm track focusing on cyclonically and anticyclonically breaking transients that 1) force organized patterns of surface turbulent heat flux and 2) have decreasing phase speeds. The decreasing phase speeds indicate a tendency for locally persistent patterns of heat flux that make breaking waves potentially more relevant to SST anomaly patterns than faster-moving storms or nonbreaking waves.

The focus of much PDO research is on the dominant, multidecadal signal of the PDO. El Niño thus appears as an important component for understanding the PDO-it has decadal energy with enough amplitude to force measurable decadal shifts in the extratropical distribution of 
transients in locations where their temperature advection patterns project onto the PDO spatial pattern. However, the unfiltered leading EOF of extratropical Pacific SSTs that is traditionally used to define the PDO index has a rich spectrum with notable interannual variability. Atmospheric variability patterns with energy on interannual time scales, particularly the PNA and NAM, are closely tied to variability in jet-level winds and therefore variability in the location of critical lines in the proximity of which Pacific Rossby waves break. Our results motivate an expanded atmospheric bridge concept wherein internal atmospheric variability is explicitly considered and RWB provides the physical mechanism for upper-tropospheric variability patterns to connect to heat exchange processes at the air-sea interface.

In this expanded conceptual model of the PDO, ENSO forces extratropical atmospheric anomalies that alter the spatiotemporal distribution of RWB directly via modification of the background flow and indirectly via modification of the probability density function of the PNA. Other variability patterns internal to the atmosphere (i.e., NAM) superpose statistically significant RWB anomalies that may interact with the RWB anomaly patterns associated with ENSO and the PNA over regions where the $\mathrm{PDO}$ is sensitive to RWB. The resulting superposed RWB anomalies integrate anomalous temperature and moisture advection patterns over several months to alter surface turbulent heat flux patterns that lead to the PDO's SST anomaly pattern.

Acknowledgments. This work was supported by NOAA Grant NA06OAR4310149. We thank two anonymous reviewers for comments that helped to improve the manuscript.

\section{REFERENCES}

Abatzoglou, J. T., and G. Magnusdottir, 2006: Planetary wave breaking and nonlinear reflection: Seasonal cycle and interannual variability. J. Climate, 19, 6139-6152.

Alexander, M. A., C. Deser, and M. S. Timlin, 1999: The reemergence of SST anomalies in the North Pacific Ocean. $J$. Climate, 12, 2419-2433.

_ I. Bladé, M. Newman, J. R. Lanzante, N.-C. Lau, and J. D. Scott, 2002: The atmospheric bridge: The influence of ENSO teleconnections on air-sea interaction over the global oceans. J. Climate, 15, 2205-2231.

Austin, P. C., and J. V. Tu, 2004: Bootstrap methods for developing predictive models. Amer. Stat., 58, 131-137.

Cayan, D. D., M. D. Dettinger, H. F. Diaz, and N. E. Graham, 1998: Decadal variability of precipitation over western North America. J. Climate, 11, 3148-3166.

Dettinger, M. D., D. R. Cayan, H. F. Diaz, and D. M. Meko, 1998: North-south precipitation patterns in western North America on interannual-to-decadal timescales. J. Climate, 11, 3095-3111.

Kirtman, B. P., and J. Shukla, 2002: Interactive coupled ensemble: A new coupling strategy for CGCMs. Geophys. Res. Lett., 29, 1367, doi:10.1029/2002GL014834.
Lau, N. C., and M. J. Nath, 1996: The role of the "atmospheric bridge" in linking tropical Pacific ENSO events to extratropical SST anomalies. J. Climate, 9, 2036-2057.

Liu, Z., and M. Alexander, 2007: Atmospheric bridge, oceanic tunnel, and global climatic teleconnections. Rev. Geophys., 45, RG2005, doi:10.1029/2005RG000172.

Mantua, N. J., and S. R. Hare, 2002: The Pacific decadal oscillation. J. Oceanogr., 58, 35-44.

- — - Y Y. Zhang, J. M. Wallace, and R. Francis, 1997: A Pacific interdecadal climate oscillation with impacts on salmon production. Bull. Amer. Meteor. Soc., 78, 1069-1079.

Martius, O., C. Schwierz, and H. C. Davies, 2007: Breaking waves at the tropopause in the wintertime Northern Hemisphere: Climatological analyses of the orientation and theoretical LC1/2 classification. J. Atmos. Sci., 64, 2576-2592.

McIntyre, M. E., and T. N. Palmer, 1983: Breaking planetary waves in the stratosphere. Nature, 305, 593-600.

Minobe, S., 1997: A 50-70-year climatic oscillation over the North Pacific and North America. Geophys. Res. Lett., 24, 683-686. 1999: Resonance in bidecadal and pentadecadal climate oscillations over the North Pacific: Role in climatic regime shifts. Geophys. Res. Lett., 26, 855-858.

Moore, G. W. K., and I. A. Renfrew, 2002: An assessment of the surface turbulent heat fluxes from the NCEP-NCAR reanalysis over the western boundary currents. J. Climate, 15, 2020-2037.

Mysak, L. A., 1986: El Niño, interannual variability and fisheries in the northeast Pacific Ocean. Can. J. Fish. Aquat. Sci., 43, 464-497.

Newman, M., 2007: Interannual to decadal predictability of tropical and North Pacific sea surface temperatures. J. Climate, 20, 2333-2356.

Orlanski, I., 2005: A new look at the Pacific storm track variability: Sensitivity to tropical SSTs and to upstream seeding. J. Atmos. Sci., 62, 1367-1390.

Schneider, N., and B. D. Cornuelle, 2005: The forcing of the Pacific decadal oscillation. J. Climate, 18, 4355-4373.

Straus, D. M., and J. Shukla, 2002: Does ENSO force the PNA? J. Climate, 15, 2340-2358.

Strong, C., and G. Magnusdottir, 2008: Tropospheric Rossby wave breaking and the NAO/NAM. J. Atmos. Sci., 65, 2861-2876.

Wallace, J. M., and D. S. Gutzler, 1981: Teleconnections in the geopotential height field during the Northern Hemisphere winter. Mon. Wea. Rev., 109, 784-812.

Wold, H. O. A., 1982: Soft modeling, the basic design and some extensions. Systems under Indirect Observation: Causality, Structure, Prediction, Vol. 2, K. G. Jöreskog and H. O. A. Wold, Eds., North-Holland, 1-54.

Wolter, K., and M. S. Timlin, 1993: Monitoring ENSO in COADS with a seasonally adjusted principal component index. Proc. 17th Climate Diagnostics Workshop, Norman, OK, NOAA/ NMC/CAC, NSSL, Oklahoma Climate Survey, CIMMS and the School of Meteorology, University of Oklahoma, 52-57.

Yeh, S.-W., and B. P. Kirtman, 2004: The impact of internal atmospheric variability on the North Pacific SST variability. Climate Dyn., 22, 721-732.

—,- , and S.-I. An, 2007: Local versus non-local atmospheric weather noise and the North Pacific SST variability. Geophys. Res. Lett., 34, L14706, doi:10.1029/2007GL030206.

Yu, B., A. Shabbar, and F. W. Zwiers, 2007: The enhanced PNAlike climate response to Pacific interannual and decadal variability. J. Climate, 20, 5285-5300.

Zhang, Y., J. M. Wallace, and N. Iwasaka, 1996: Is climate variability over the North Pacific a linear response to ENSO? J. Climate, 9, 1468-1478. 